\title{
Performance evaluation of solar parabolic trough driven water purification system
}

\author{
Kriti Srivastava $^{1}$, Prashant Saini ${ }^{2}$ \\ ${ }^{I *}$ Department of Mechanical Engineering, IETDr.RLA University, Faizabad, INDIA \\ ${ }^{2}$ Department of Mechanical Engineering, Madan Mohan Malaviya University of Technology, Gorakhpur, INDIA \\ "Corresponding Author: e-mail: kritisrivastava.17@gmail.com
}

\begin{abstract}
Application of solar energy to purify the water is advancing rapidly since it is an attractive alternative because of its simple technology; non-requirement of skilled labor for maintenance work, low energy consumption and no fuel is required for operating such water purification unit. This paper deals with the performance evaluation of the solar water purification at Mechanical Engineering Department MMMUT Gorakhpur, India. To perform this experiment, parabolic trough of fixed rim angle and length is considered. Based upon rim angle and length other pertinent parameters are calculated and selection of materials for fabrication of the unit is done. After that solar water purifier unit is fabricated. The solar parabolic collector utilizes the concentrating solar power technology to concentrate the solar insolation. The performance of parabolic trough is evaluated by considering the effect of glass cover on the concentrator. Various results are plotted between the temperature of the fluid and time keeping other parameters held fixed. Further a comparative study is performed for solar water purification unit with and without glass cover. The purity of water is measured based on its $\mathrm{pH}$ value and total dissolved solid (TDS).
\end{abstract}

Keywords: Solar energy, concentrating solar power, solar water purifier, total dissolved solid, $\mathrm{pH}$

DOI: http://dx.doi.org/10.4314/ijest.v13i1.5S

Cite this article as:

Srivastava K., Saini P. 2021. Performance evaluation of solar parabolic trough driven water purification system, International Journal of Engineering, Science and Technology, Vol. 13, No. 1, pp. 32-38. doi: 10.4314/ijest.v13i1.5S

Received: December 1, 2019; Accepted: February 5, 2021; Final acceptance in revised form: March 31, 2021

This paper was earlier presented at the International Conference on Energy, Environment \& Material Sciences (ICE2M), 1-3 December 2019 and substantially improved for this Special Issue. Guest Editor: Dr. Sri Niwas Singh, Professor (HAG), Department of Electrical Engineering, Indian Institute of Technology Kanpur, 208016 (U.P.) India, former Vice-Chancellor, Madan Mohan Malviya University of Technology Gorakhpur (April 2017 to July 2020).

\section{Introduction}

Solar energy is a renewable energy that is most abundant, inexhaustible and universal source of energy. Solar insolation drives all-natural cycles and processes such as rain, wind, photosynthesis, ocean currents and several others which are important for life. The provision of pure and clean water is becoming an increasingly important concern in many parts of the world. Water is considered among one of the most abundant resources on earth, covering approximately three fourths of the earth's surface.

$97 \%$ of water present on the earth is saline in nature that is present in the oceans and rest 3\% of it that may be considered fresh water is present at poles that is in the form of ice. Lakes and rivers satisfy most of needs of human and animal. Among this $3 \%$ of fresh water approximately $70 \%$ of them is in the form of snow caps, glaciers and ice. And rest that is (30\%) of all fresh water is available as a deep underground water. The use of this freshwater in a sustainable manner is main concern for human beings. Fast growing population leads for continuous increase in need and demand for fresh and pure drinking water. This leads to scarcity of 
fresh water and decrease in level of water table in many parts of world. This trouble is mainly due to non-rational use of water resource by human beings. Many areas in India face a huge fresh-water shortage because of the unplanned mechanism and various types of pollution generated by human activities.

Key points to choose the problem.

1) Solar power that is the energy from the sun is ecofriendly that is it causes no harm to environment unlike other fossil fuels \& it provides a sustainable way of energy production and utilization.

2) Solar water treatment can proof particularly much beneficial for rural communities, as they lack in other systems or other forms of water distillation infrastructure and more importantly, the power that is electricity to run such purification infrastructures.

3) The most positive and promising feature about solar assisted water purification techniques are that the requirement of fuel is fulfilled by the energy obtained from the sun.

4) It is basically due to the lack of fuel that makes applications of solar energy relatively superior than other conventional energy sources as it does not cause pollution (ozone depletion, global warming, acid rain,) or other health hazards that is associated with pollution.

5) Solar water purifiers generally do not require any moving parts so we can say that it may have longer life span.

6) Solar water purifier is generally an effective alternative for treatment of contaminated water where fuel or electric are unavailable or prohibitively expensive.

7) Maintenance of such type of water purifier is also negligible.

8) Water wastage can also be minimized by using such infrastructure. In many purification techniques there is huge wastage of water and most of the input water flows out without any use.

Many distillation techniques were developed that utilizes the solar energy to run the purifying unit. Aybar et al. (2005) studied an inclined solar water distillation system by testing under actual environmental conditions of Northern Cyprus. The result shows that the fresh-water generation rate increased two to three times when wicks were used instead of a bare plate. Duffet al. (2005) designed and tested a passive solar water pasteurization system working on density difference flow principles. The system contains no valves and flow was regulates on the basis of density difference between two columns of water. Prasad and Tiwari (2006) experimentally analyzed the double effect still coupled along with a parabolic concentrator. They observed wastage of heat from upper basin resulting in decrement of total yield per hour. They concluded that maintaining glass cover temperature is crucial factor. Nafeyet al. (2007) have done experiment-based study on a flat plate solar collector of capacity of about 1.04 to 1.45 $\mathrm{kg} / \mathrm{m}^{2}$ per day. A mathematical model was developed to examine the productivity of the system.

Compain et al. (2012) has studied solar energy for water desalination. The work suggested different solutions for the commonly used solar energy production technology to be compatible with desalination. The main objective of the work was to assess the profitability and feasibility of the replacement of fuel-based energy for desalination plants by renewable energy. Blanco et al.(2012) performed experiment on parabolic through collector with capacity of $3.5 \mathrm{~m}^{3} / \mathrm{d}$. They used different processes such as MED, MSF, RO together with PTC. Their study was mainly based on an economic evaluation and thermodynamic characterization of various configurations for coupling parabolic through with desalination facilities. Li et al. (2014) reviewed different solar desalination research activities followed by discussion of various solar assisted desalination processes. They have mentioned various solar water distillation techniques. Peter et al. (2014) have worked on a solar water treatment system for remote applications. A continuous feed water treatment facility with low cost has been developed. The facility utilizes solar (UVA) insolation for the treatment of pathogens. Rizwan et al. (2014) has experimentally analyzed the parabolic trough for the water distillation and has analyzed two cases by varying the height of the inlet with respect to parabolic trough base. Phalak et al. (2017) have proposed model of solar RO water purifier by using solar PV cell for remote application.

As per the literature review, it is found that the solar stills cannot be used effectively for domestic purposes since it requires a large area and its efficiency is also low. The use of RO technology and various other technologies such as multi-effect distillation, multi flash distillation etc. requires large initial investments. It has been observed that there is huge wastage of water in reverse osmosis process. Taking these problems into account it is observed that the possible solution for this is to use concentrated solar power as it gave better efficiency for the desired purpose and wastage of water is also less as compared to other distillation processes.

The main motivation for this work is the fact that solar water purifier generally an effective alternative for treatment ofcontaminated water where fuel or electric are unavailable or prohibitively expensive. Solar water treatment can proof particularly much beneficial for rural communities, as they lack in other systems or other forms of water distillation infrastructure and more importantly, the power that is electricity to run such purification infrastructures. Water wastage can also be minimized by using such infrastructure. In many purification techniques there is huge wastage of water and most of the input water flows out without any use. 


\section{Proposed System Description}

Parabolic trough collector that comes under the category of line focusing collectors is often used in concentration collectors. Solar radiation coming from the particular direction is collected over the area of the reflecting surface and is focused along the line. The north-south orientation of the reflector trough permits more solar energy to be focused than the east west arrangement.

\subsection{Material selection and calculation of the parameters}

To perform this experimentation the parabolic trough of fixed rim angle and length was considered. Based on this rim angle and length the various other parameters such as aperture and focal length are calculated and selection of various materials for the fabrication of the unit was done. The various parameters of the purification unit calculated are shown in Table 1. The parabolic structure is made with the galvanized iron sheet of thickness $0.6 \mathrm{~mm}$. The reflecting part is fixed on this structure. It consists of a cylindrical parabolic reflector and a metal tube receiver at its focal plane.

The aperture diameter, rim angle, the absorber size and shape is used to define the concentrator. Reflectors may be aluminum sheet, aluminized Mylar sheet or curved silver glass. Since it is difficult to curve a large glass, aluminum sheet was used in the shape of the parabolic cylinder. The reflectivity of aluminum is 0.92 . The conductivity of aluminum is $225 \mathrm{~W} / \mathrm{mK}$. The thickness of aluminum sheet is taken as $0.5 \mathrm{~mm}$. The receiver or absorber tube absorbs the incoming solar insolation and transforms them into thermal energy. This thermal energy is given to the fluid that is flowing into the tube. The absorber tube may be made of mild steel or copper and is coated with a heat resistant black paint. It was painted with black paint to increase the absorption of heat. The conductivity of the copper is higher than steel that is why here copper tube is used. The absorptivity of copper is 0.4 . The thermal conductivity of copper is $384 \mathrm{~W} / \mathrm{mK}$. Glass cover is generally used to trap the heat within the parabolic collector. Glass cover minimizes the heat loss by convection through system and thus improves the transfer of heat from absorber tube to water (working fluid).The conductivity of glass is $0.75 \mathrm{~W} / \mathrm{mK}$. It acts as a heat trap.The PVC pipes and couplings are used to connect the inlet and outlet tank at both ends of the parabola. Tanks of capacity of 5 liters are taken. Two stopper valves were used both at the inlet and outlet section in order to control the flow of the water through pipes.

\subsection{Working}

The principle on which this system works is that the solar insolation coming from the particular direction is collected over the area of the parabolic collector having reflecting surface and then the entire radiation is focused along the line of the trough. Cylindrical parabolic concentrators have the absorber tube at its focal axis. The absorber or the receiver is tubular in form and the fluid flows in this tube only. In order to get the optimum result the solar parabolic collector is to be steered along sun's direction. An inlet tank of 5 liters capacity has been taken. Inlet was taken from a tank at a height of $1 \mathrm{~m}$ from the base of the parabolic trough. A PVC pipe was used to connect the tank and inlet of the parabolic trough. At the inlet a small section of transparent pipe was used. To measure the mass flow rate, stop valve at the outlet was open by small amount. At the outlet a one liter beaker was placed. The time in which the 1 liter beaker was filled was taken. Mass flow rate was found to be $1.51 \mathrm{t} / \mathrm{hr}$. After the calculation of the mass flow rate, it was observed that the conditions were good for testing. Initial temperature of water in the tank was tested. It was $28^{\circ} \mathrm{C}$. Testing was started at a local time of 9A.M. Temperature of water was measured after every one hour intervals. The stop valve at the inlet tank was open and the copper tube was filled up to a certain level. The level was decided such that at the outlet section the stop valve was half opened so that only vapor comes out of it. The vapor was condensed and collected in the outlet. Then the $\mathrm{pH}$ testing and TDS testing of the water was done.

The efficiency for the parabolic trough can be calculated by using the formula (Ground Water Year Book- India 2013-14)

$$
\eta=\frac{Q}{I A}
$$

where $\mathrm{Q}$ is the heat gained by the liquid given by

$$
Q=m \times c_{p} \times\left(T_{f}-T_{i}\right)
$$

I is the solar insolation $\left(\mathrm{W} / \mathrm{m}^{2}\right)$ and A is the area of the collector $\left(\mathrm{m}^{2}\right)$.Mass flow rate $(\mathrm{m})$ was found to be $1.51 \mathrm{tr} / \mathrm{hr}$.The reading are taken with the glass cover and other without the glass cover. 


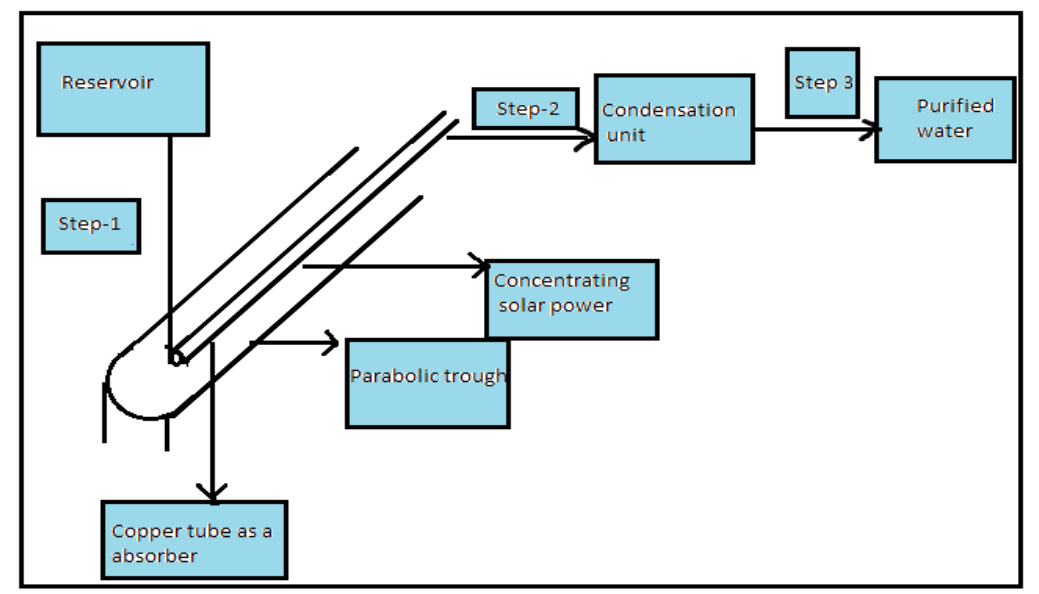

Figure 1. Flow diagram of set-up

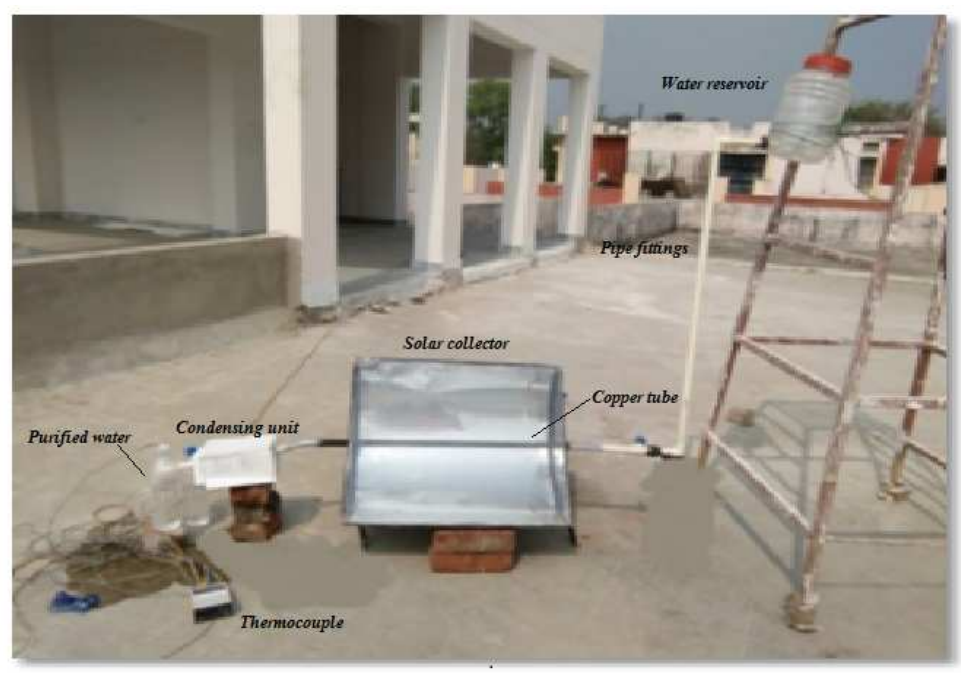

Figure 2. Experimental set-up

\section{Results and Discussion}

After performing the experiment at particular weather conditions, following results are obtained which are discussed below.

\subsection{Cylindrical parabolic trough with glass cover}

In case 1 the cylindrical parabolic trough is tested in the particular weather condition and the effect of the glass cover was observed. The temperature of the water in the system was recorded with the help of thermocouple for every 1 hour.

Weather condition: Dry weather.

Initial temperature for water: $28^{\circ} \mathrm{C}$ around 9 a.m. IST.

Maximum observed temperature of water: $95^{\circ} \mathrm{C}$ around 1 p.m.IST.

As it can be clearly seen from figure 3 that the maximum temperature of the fluid obtained was $95^{\circ} \mathrm{C}$ at around 1 p.m. IST.

The maximum solar insolation observed was $711 \mathrm{~W} / \mathrm{m}^{2}$ at around 1 p.m.IST.

The efficiency of the parabolic trough with the glass cover was found to be $63.79 \%$.

The Final $\mathrm{pH}$ of water was found between 7-7.5.Initial Total Dissolved Solid(TDS) of water was found to be 330ppm and final Total Dissolved Solid of water was found to be 300ppm.

\subsection{Cylindrical parabolic trough (without glass cover)}

In case 2 the cylindrical parabolic trough is tested without the glass cover. The temperature of the water was recorded for every 1 hour with the help of thermocouple. Initial temperature during observation: $28{ }^{\circ} \mathrm{C}$ around 9 a.m. IST. Maximum temperature was observed to be $66^{\circ} \mathrm{C}$ around 1 P.M. IST. The initial $\mathrm{pH}$ of water was found to be 7-7.5. It is clear from the figure 4 the maximum 
temperature of the water was reaches up to $66^{\circ} \mathrm{C}$ at around $2 \mathrm{p}$.m. IST.Maximum solar insolation was found to be $735 \mathrm{~W} / \mathrm{m}^{2}$ at around 2 p.m.IST. The efficiency of the parabolic trough without the glass cover was found to be $39.8 \%$. This reduction in efficiency is due to energy loss from the concentrator. Final TDS of water was found to be $310 \mathrm{ppm}$. As it can be seen in the figure 5 , the maximum temperature attained by the fluid in the parabolic trough when glass cover is used is approximately $95^{\circ} \mathrm{C}$. And the maximum temperature attained by the fluid is $66^{\circ} \mathrm{C}$ when glass cover is not using. From the above two temperatures, it is clear that glass traps the heat inside it and helps in attaining the much higher temperature.

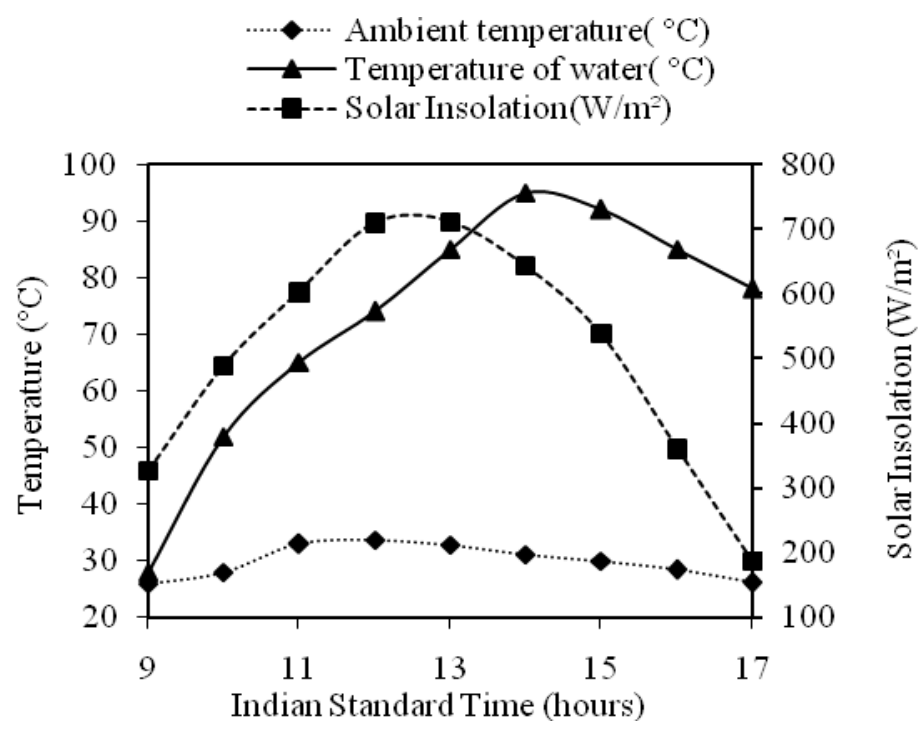

Figure 3. Temperature variation and solar insolation with time

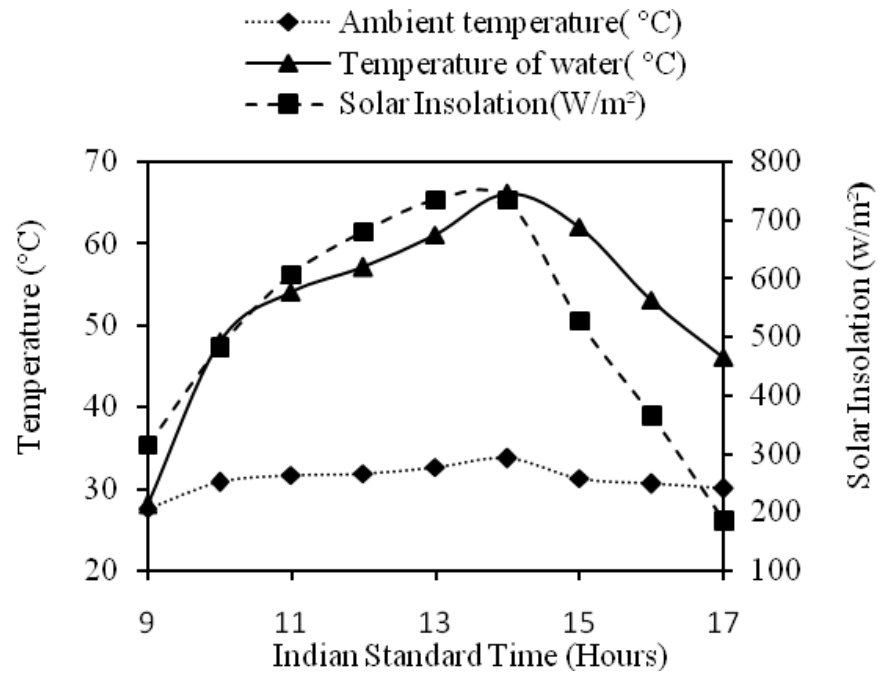

Figure 4. Temperature variation and solar insolation with time 


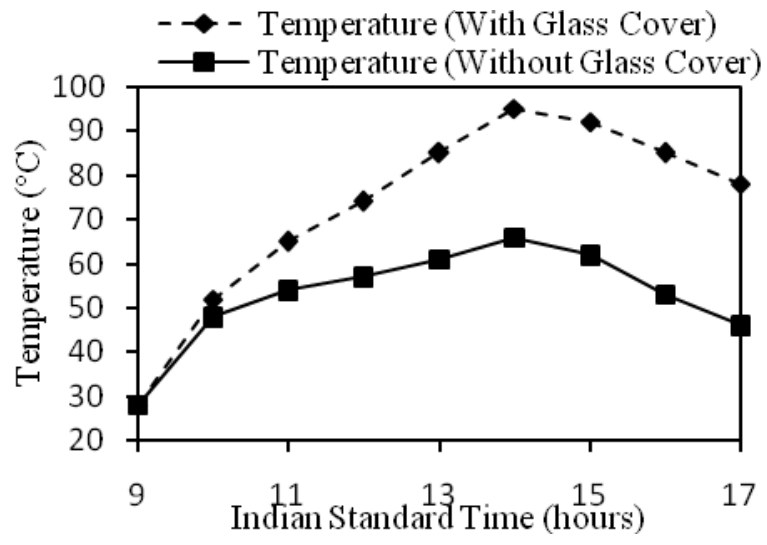

\section{Conclusions}

Figure 5. Temperature of fluid with glass cover and without glass cover

Current work dealt with water purification using a parabolic trough collector experimentally. The system was constructed and evaluated for its efficiency. Based on results obtained following conclusions can be drawn:

- The maximum temperature recorded in cylindrical parabolic trough with glass cover was $95^{\circ} \mathrm{C}$ and the maximum temperature recorded in cylindrical parabolic trough without glass cover was $66^{\circ} \mathrm{C}$.

- It may be concluded from above that the efficiency of the cylindrical parabolic trough with glass cover was $63.79 \%$ and that without glass cover was $39.4 \%$. That means the glass cover was effective in trapping the solar insolation inside the parabolic trough.

- There was no considerable change found in $\mathrm{pH}$ value of the water after the condensation. The $\mathrm{pH}$ value remained in the range of 7-7.5. Thus, we can conclude that there is slight effect of temperature change on the $\mathrm{pH}$ which can be neglected.

- The total dissolved solid was reduced from $330 \mathrm{ppm}$ to $300 \mathrm{ppm}$ in case of cylindrical parabolic trough with glass cover and in case of parabolic trough without glass cover it reduced from $330 \mathrm{ppm}$ to $310 \mathrm{ppm}$.

- This solar water purification system can prove to be beneficial for the people of rural areas as it is cost effective, requires little maintenance and can be frequently used to get pure drinking water where the infrastructure to run such systems are absent.

\section{References}

Aybar H.S., Egelioglu F. and Atiko I.U., 2005. An inclined solar water distillation system. Desalination, Vol. 180, pp. 285-289.

Alnaimat F. and Klausner J.F., 2012. Solar diffusion driven desalination for decentralized water production. Desalination, Vol. 289, pp. 35-44.

Balan R., Chandrasekaran J., Shanmugan S., Janarthanan B. and Kumar S., 2011. Review on passive solar distillation. Desalination and Water Treatment, Vol. 28, pp. 217-219.

Blanco J., Palenzuela P., Padilla A., Zaragoza G. and Ibarra M., 2013. Preliminary thermo economic analysis of combined parabolic trough solar power and desalination plant in port Safaga (Egypt). Desalination and Water Treatment, Vol. 51, pp.1887-1899.

Compain P., 2011. Solar Energy for Water desalination. 1st International Symposium on Innovation and Technology in the Phosphate Industry [SYMPHOS 2011].

Duff W.S. and Hodgson D.A., 2005. A new passive solar water pasteurization system. Desalination, Vol. 190, pp. 125-135.

Ground Water Year Book- India 2013-14. Central Ground Water Board.Ministry of Water Resources, 2012.

Kalt P., Birzer C., Evans H., Liew A., Padovan M. and Watchman M., 2014. A solar disinfection water treatment system for remote communities humanitarian technology. Science Systems and Global Impact 2014, HumTech2014.

Kharabsheh A.I. and Goswami Y., 2003.Analysis of an innovative water desalination system using low grade solar heat. Desalination, Vol. 156,pp.323-332.

Li C., Goswami Y. and Stefanakos E., 2013. Solar assisted sea water desalination -A review. Renewable \& Sustainable Energy Reviews, Vol 19, pp.136-163.

Nafey A.S., Mohamad M.A., El-Helaby S.O. and Sharaf M.A., 2007. Theoretical and experimental study of a small unit for solar desalination using flashing process. Energy Conversion and Management, Vol. 48, pp.528-538.

Phalak M., Kurkure P., Bhangale N., Deshmukh V., Patil M. and Patil M.H. 2017. Solar powered reverse osmosis water purifier. International Journal for Research in Engineering Application \& Management, Vol. 3, No. 1, pp. 56-59. 
Prasad B. and Tiwari G.N., 2006. Analysis of double effect active solar distillation. Energy Conversion and Management, Vol. 37, pp. 1647-1656.

Rizwan M., Raheem A., Junaidi M., Suleman M. and Hussain M.A., 2014. Experimental verification and analysis of solar parabolic collector for water distillation. International Journal of Engineering Research, Vol. 3, No. 10, pp. 588-593.

Singh R.P., 2013. Water desalination: The role of RO and MSF. Journal of Environmental Science, Toxicology and Food Technology, Vol. 6, pp. 61-65.

Sukhatme S.P., 2016. A book on solar energy. Tata McGraw-Hill Education.

\section{Biographical notes}

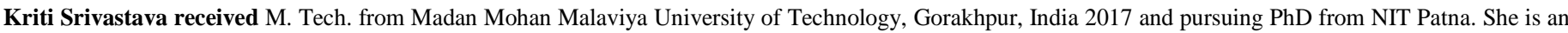
Assistant Professor in the Department of Mechanical Engineering, IETDr. RLA University, Faizabad, India. Her research interests include thermal engineering and

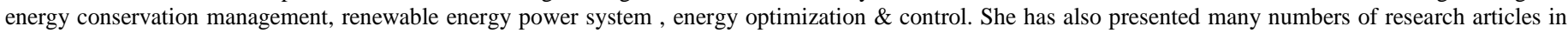
national and international conferences also in international journals.

Prashant Saini received M. Tech. from National Institute of Technology Warangal, India. He is an Assistant Professor in the Department of Mechanical Engineering, Madan Mohan Malaviya University of Technology Gorakhpur, India. He has more than six years of experience in teaching and research. His current area of research includes solar energy utilization, heat transfer, efficient energy conversion technologies and combined cooling, heating and power systems. 